\title{
HMGB1 inhibition to ameliorate organ failure and increase survival in trauma
}

Zhangsheng Yang ${ }^{1 \dagger}$, Milomir O. Simovic ${ }^{1,2 \dagger}$, Peter R. Edsall ${ }^{1}$, Bin Liu ${ }^{1}$, Tomas S. Cancio ${ }^{1}$, Andriy I. Batchinsky ${ }^{1,2}$, Leopoldo C. Cancio ${ }^{1 *}$, Yansong $\mathrm{Li}^{1,2 *}$

${ }^{1}$ US Army Institute of Surgical Research, JBSA Fort Sam Houston, TX, 78234, USA, ${ }^{2}$ The Geneva Foundation, Tacoma, WA 98402, USA

†These authors contributed equally to this work.

*Corresponding authors:

Dr. Yansong Li, ysli916@gmail.com

Dr. Leopoldo C. Cancio, Leopoldo.c.cancio.civ@mail.mil

\begin{abstract}
Several preclinical and clinical reports have demonstrated that levels of circulating high mobility group box 1 protein (HMGB1) are increased early after trauma and are associated with systemic inflammation and clinical outcomes. However, the mechanisms of the interaction between HMGB1 and inflammatory mediators that lead to the development of remote organ damage after trauma remain obscure. HMGB1 and inflammatory mediators were analyzed in plasma from 54 combat casualties, collected on admission to a military hospital in Iraq, and at 8 and 24 hours after admission. Forty-five (83\%) of these patients had traumatic brain injury (TBI). Nine healthy volunteers were enrolled as controls. HMGB1 plasma levels were significantly increased in the first 8 hours after admission, and were found to be associated with systemic inflammatory responses, injury severity score, and presence of TBI. These data provided the rationale for designing experiments in rats subjected to blast injury and hemorrhage, to explore the effect of
\end{abstract}


HMGB1 inhibition by CX-01. Animals were cannulated, then recovered for 5-7 days before blast injury in a shock tube and volume-controlled hemorrhage. Blast injury and hemorrhage induced an early increase in HMGB1 plasma levels that coincided with severity of tissue damage and mortality. CX-01 inhibited systemic HMGB1 release, decreased local and systemic inflammatory responses, significantly reduced tissue and organ damage, and tended to increase survival. These data suggest that CX-01 has potential as an adjuvant treatment for traumatic hemorrhage.

Keywords: HMGB1, trauma, hemorrhagic shock, inflammation, multiple organ failure

\section{INTRODUCTION}

Trauma/hemorrhage $(\mathrm{TH})$ is the leading cause of death on the battlefield, and, for those under the age of 45, in the civilian world as well [1]. However, two-third of severe trauma patients succumb to causes other than exsanguination [2-3]. Tissue injury and hemorrhage involve ischemia and reperfusion injury (IRI) and initiate a series of prompt innate immune responses, including both pro-inflammatory and anti-inflammatory processes. In the event of severe injury, the inflammatory response to blood loss and tissue damage can start within minutes [3-6].

Trauma immediately induces release of damage-associated molecular patterns (DAMPs), such as high-mobility group box 1 protein (HMGB1, also known as amphoterin) [7-9], IL-1, IL33, calgranulins, histones, heat-shock proteins, nucleic acids, and adenosine triphosphate (ATP) [9-11], matricryptins [12], free heme [9, 13], cold-inducible RNA-binding protein [14], and mitochondrial DNA [15]. DAMPs in conjunction with pathogen-associated molecular patterns (PAMPs) promptly activate the complement [16], coagulation [17], and kallikrein-kinin systems, 
[18], ultimately leading to trauma-induced immune dysfunction, infectious complications, and multiple-organ failure (MOF). Although trauma care has gradually improved, therapeutic treatment of these sequelae remains challenging.

Extracellular HMGB1 (eHMGB1) has a strong pro-inflammatory effect [19]. Although HMGB1 as a host product is sterile itself, it signals through toll-like receptors (TLR2, TLR4), the receptor for advanced glycation end products (RAGE), NF- $\mathrm{B}$-inflammasome, and/or CXCL-12CXCR4-NF- $\mathrm{BB}$-inflammasome axis, and induces organ damage even in the absence of infection [20-22]. HMGB1 released from damaged tissue and the activated innate immune system [23] signals tissue damage to macrophages and dendritic cells (DCs) to secret HMGB1 in a vicious circle-pattern. Thus, HMGB1 holds a central role in conveying the local and systemic responses to noxious factors, including trauma and sepsis [24].

Our previous studies have shown the beneficial effects of pharmacological manipulation of complement activity on survival, hemodynamics, fluid requirements, tissue damage, and local and systemic inflammation in rats and swine in short-term studies ( $<6$ hours) after TH [25-28]. In experiments with rats exposed to $\mathrm{TH}$, we have recently shown that the inhibition of the complement terminal pathway (CTP) reduced HMGB1 levels in the blood, and coincided with beneficial treatment (unpublished data). This finding, and the upstream position of HMGB1 relative to the plasma cascade systems [16-18], identify HMGB1 as a biomarker and therapeutic target in processes in which inflammation plays a key role [29, 30].

Although both unfractionated heparin and low-molecular-weight heparin inhibit the effects of HMGB1 by interfering with its interaction with RAGE, their anticoagulant activity limits their use in TH. CX-01 (2-O, 3-O-desulfated heparin) is a novel HMGB1 inhibitor with <5\% anticoagulant activity. We hypothesized that treatment with CX-01 would alleviate tissue damage 
and improve survival in a rat model of $\mathrm{TH}$ that recapitulates the immunological responses seen in injured patients [31].

\section{MATERIALS AND METHODS}

\section{Clinical study design}

The Institutional Review Board (IRB) of Brooke Army Medical Center reviewed and approved the research protocol and granted a waiver of consent for blood sampling as a minimalrisk intervention. The study in trauma patients was designed to identify the clinical significance of early HMGB1 release in military casualties admitted to a US Army Combat Support Hospital (Role 3) in Baghdad, Iraq over a one-year period. Foreign nationals, prisoners, enemy combatants, children, and any patient undergoing therapeutic anticoagulation were excluded. Citrated plasma was collected from trauma patients after admission to the emergency department $(n=54,53$ males and 1 female; median age $=25$ years, interquartile range from 22 to 30 years $)$, and if available, 8 hours $(n=23)$ and 24 hours $(n=9)$ later. At these later time points, samples were collected after patients had received appropriate clinical care, including surgery and resuscitation. On admission (45-60min after injury) and during the first 24 hours, the clinical characteristics and demographic information of the patients were recorded, including base excess, mean arterial pressure (MAP), 
blood product transfusion units, and systemic inflammatory response syndrome (SIRS) score. Most casualties $(83 \%, \mathrm{n}=45)$ suffered traumatic brain injury from explosions. Of the 9 healthy controls, 6 were male and four were female with a mean age of $35.4 \pm 9.1$ years.

Blood collected at the hospital was processed according to standard clinical practice [30] and the resultant plasma was frozen and transported to the US Army Institute of Surgical Research as described in [32] and stored at $-80^{\circ} \mathrm{C}$ until analysis. Nine healthy volunteers were enrolled at the authors' laboratory as reference controls. Volunteers were 18 years or older with no significant medical conditions. Blood samples were collected once for the analysis of the levels of HMGB1, cytokines, selected complement components and blood chemistry.

\section{Animal study design}

The USAISR Institutional Animal Care and Use Committee approved all research conducted in this study. Experiments in rats subjected to TH were used to evaluate the efficacy of drug CX-01 (Chimerix, Inc., Durham, NC). The effects of inhibition of HMGB1 on tissue damage and survival of the injured rats were examined to verify the therapeutic potential of CX-01.

After recovery (5-7 days) from surgical cannulation and prior to $\mathrm{TH}$, animals were randomly assigned to one of three groups: (1) the injured/untreated group $(n=9)$ underwent blast injury and hemorrhage $(\mathrm{B}+\mathrm{H})$, and sham treatment with saline vehicle; $(2)$ the injured/treated group (CX-01, n=6) underwent blast injury and hemorrhage, and treatment with CX-01; and (3) the time-control group (Control, $n=6$ ) underwent all procedures except $\mathrm{B}+\mathrm{H}$ and subsequent sham treatment (Figure 4A). There were no exclusions from the experiments, and drug and vehicle administration were non-blinded. A randomized blinded code for histological sections was used. 


\section{Surgical procedures and trauma induction in rats}

Specific pathogen-free adult male Sprague-Dawley rats (10-12 weeks old), weighing 350$475 \mathrm{~g}$ were purchased from Charles River Laboratories (Wilmington, MA) for use in this study. Under anesthesia of $1-2.5 \%$ isoflurane, the carotid artery and jugular vein were cannulated in all rats. The cannulated animals went through a 5-7 day recovery period. Blast injury was conducted as described previously $[33,34]$. Briefly, the rats were anesthetized with ketamine/xylazine (60/5 $\mathrm{mg} / \mathrm{kg}$ body weight) via intra-peritoneal injection, and then placed on a rack holder, which was wheeled into the end of the expansion chamber of a compressed air-driven shock tube [31]. During the blast process, the animals were immobilized to prevent movement by blast impact and subsequent secondary or tertiary blast injuries. The animals in the prone position with their heads turned to the blast wave were exposed to single mild-moderate blast injury. Blast severity was similar for both groups. For the sham group, blast data were $\mathrm{BOP}=117.26 \pm 1.36 \mathrm{kPa}, \mathrm{t}+=3.29 \pm$ $0.01 \mathrm{~ms}$, and $\mathrm{I}=141 \pm 0.87 \mathrm{kPa}-\mathrm{ms}$. For the $\mathrm{CX}-01$ group, blast data were $\mathrm{BOP}=117.48 \pm 1.82$ $\mathrm{kPa}, \mathrm{t}+=3.38 \pm 0.03 \mathrm{~ms}$, and $\mathrm{I}=145 \pm 0.39 \mathrm{kPa}-\mathrm{ms}$ (Table 1$) .15 \mathrm{~min}$ after blast exposure, animals were subjected to volume-controlled hemorrhage over 15 minutes. The $52 \%$ estimated total blood volume $(\mathrm{ETBV})$ was calculated using the following formula: $\mathrm{ETBV}(\mathrm{ml})=$ weight in $\mathrm{kg} \times 60$ $\mathrm{ml} / \mathrm{kg}$. After hemorrhage, the animals were maintained for 30 minutes (shock phase), then received two times the shed blood volume of Plasma-Lyte A. The animals were monitored under anesthesia for 3 hours after the end of the shock phase $(\mathrm{H})$ (see Figure 4A), then returned to their cages and observed for 24 hours. In the CX-01 group, three doses of CX-01 (25 mg/kg of body weight) were administered. The first dose was given intravenously 15 minutes after blast but before hemorrhage, the second dose was administered at $2 \mathrm{~h}$ after blast, and the third dose was administered subcutaneously at 10 hours after blast. The CX-01 dose of $25 \mathrm{mg} / \mathrm{kg}$ reflects the standard human 
unfractionated heparin intravenous dosage and has previously shown to result in a near complete inhibition of airway HMGB1 release in mice with Pseudomonas pneumonia [35]. Rats in the sham group received equal volumes of saline at the same time points.

During the observation period, the mean arterial pressure was recorded by a BIOPAC data acquisition system (BIOPAC Systems, Inc., Goleta, CA). Blood samples were collected before the blast, 15 min after blast, at the end of hemorrhagic shock (60 min after blast), and at 2, 4, and 25hours blast after injury. The blood chemistry was analyzed using an i-STAT (Abbott Laboratories, Chicago, IL), and the $\mathrm{PaO}_{2} / \mathrm{FiO}_{2}$ ratio (PFR) was based on collected i-STAT data.

\section{Assays}

Assessment of complement factors in human/rat plasma

Quantitative levels of complement factors in human plasma, including C3a, C5a, sC5b-9, $\mathrm{Bb}$ and $\mathrm{C} 4 \mathrm{~d}$, were measured using commercial enzyme-linked immunosorbent assay (ELISA) kits according to the manufacturer's instructions (Quidel, San Diego, CA). Rat plasma levels of complement C3 and C1q were assessed using ELISA kits (abcam, Cambridge, MA).

\section{Measurement of human cytokines}

Human cytokines in plasma were analyzed using Bio-Plex® Pro Human Cytokine 27-plex Assay (BIO-RAD, Hercules, CA) according to the manufacturer's instructions.

\section{Analysis of total protein in human plasma}

Levels of total protein in plasma were measured using a bicinchoninic acid protein assay kit (Pierce, Rockford, IL) according to the manufacturer's instructions.

\section{Hemolytic complement activity assay}


The complement hemolytic 50\% activity (CH50) assay was performed to determine the function of the complement classical pathway as previously described [34]. Briefly, antibodysensitized chicken red blood cells (Colorado Serum Company, Denver, CO, catalog \#31151) were incubated for $30 \mathrm{~min}$ at $37^{\circ} \mathrm{C}$ with serial dilutions of rat serum samples in gelatin-veronal buffer $\left(\mathrm{GVB}^{++}\right.$buffer, Complement Technology, Tyler, TX, catalog \#B100). After centrifugation, the supernatant was transferred to a new plate, and the absorbance of supernatant was determined at $405 \mathrm{~nm}$ by SpectraMax microplate reader (Molecular Devices). The fold serum dilution inducing $50 \%$ of complement hemolytic activity was determined and presented as the $\mathrm{CH} 50$ value.

Measurement of HMGB1 and MPO levels in human and rat plasma

HMGB1 and myeloperoxidase (MPO) were measured using ELISA kits obtained from IBL International (Morrisville, NC) and Hycult Biotech (Plymouth Meeting, PA), respectively. HMGB1 and MPO were determined by quantitative sandwich enzyme-linked immunosorbent assay (ELISA) according to the manufacturer's instructions.

\section{Tissue pathological evaluation and semi-quantitative scoring}

Histological images for each individual rat tissue were recorded with 10x objective under a slide scanner (Axio Scan. Z1 v1.0, Zeiss, Germany), and representative images of each group were presented (magnification, 400x). Semi-quantitative scoring of lung, brain and liver tissues was performed by a pathologist blinded to the treatment information, and the criteria for the evaluation of histological injury scores are as follows.

For the lung injury score, four parameters (alveolar fibrin edema, alveolar hemorrhage, septal thickening, and intra-alveolar inflammatory cells) were scored on each hematoxylin and eosin 
(H\&E) stained slide based on: 1 ) severity ( 0 : absent; 1, 2, 3 and 4 for increasingly severe changes); and 2) the extent of injury (0: absent; $1:<25 \% ; 2: 25-50 \% ; 3: 50-75 \% ; 4>75 \%)$. Total injury score for each slide was calculated as the sum of the severity plus the extent of injury (12).

For brain injury score, we undertook the approach previously described (10). Two parts of the brain tissue were scored, including the frontal cortex and hippocampus. Damage was assessed using 5 distinct morphological parameters: neuronal morphological changes (shrinkage of the cell body, pyknosis of the nucleus, disappearance of the nucleolus, and loss of Nissl substance, with intense eosinophilia of the cytoplasm), neuronal loss, cytotoxic edema, vasogenic edema, and inflammatory cell infiltration in the brain cortex. The changes were scored according to their extent (score $0,1,2,3$, and 4 for an extent of $0 \%,<25 \%, 25-50 \%, 50-75 \%$, and $75-100 \%$, respectively) and the severity of the injury ( score $0=$ normal histology, score $1=$ slight, $2=$ mild, $3=$ moderate, and $4=$ severe alterations).

For the hepatic injury score, four parameters, including vascular congestion, hepatocyte death, degeneration, and inflammation were considered (12), and these parameters were assayed for severity (score 0 for no change, score 1, 2, 3 and 4 for more severe changes) and for the extent of injury (0: absent; $1:\langle 25 \% ; 2: 25-50 \% ; 3: 50-75 \% ; 4:>75 \%)$. The injury score represents the sum of the extent and the severity of injury.

\section{Statistical analysis}

All statistical analyses were performed using GraphPad Prism 6.0 (GraphPad Software, San Diego, CA). Demographic data are presented as interquartile ranges (IQR) or percentages as appropriate. Other data are presented as mean \pm SEM. Intergroup comparisons for complement 
factors and cytokines in patients or animals were assessed by Mann-Whitney U test, or two-tailed unpaired $t$-test with Welch's correction. Correlation analyses were analyzed by Spearman's rank correlation test. For animal survival analysis, the log-rank Mantel-Cox test was performed. Twoway ANOVA was performed to compare the animal groups on particular variables. $P<0.05$ was considered significant. All data were included and none were treated as outliers.

\section{RESULTS}

\section{Patient demographics and clinical outcomes}

We investigated 54 injured combat casualties, with injuries from blast exposure $(68 \%$, $\mathrm{n}=37)$, gunshot wound (GSW, 26\%, $\mathrm{n}=14)$, burns $(4 \%, \mathrm{n}=2)$, and one motor vehicle accident $(2 \%$, MVA). Forty-five (83\%) of the 54 patients had traumatic brain injury (TBI), of whom most (80\%) sustained a mild TBI. During the hospital treatment, mechanical ventilation was used in 7 patients (13\%), and 5 patients (9\%) died. All patients received operative care and fluids.

HMGB1 plasma levels, and correlations with inflammatory mediators and clinical features in military casualties

Plasma levels of HMGB1 were significantly higher in combatants on admission to hospital and at 8 hours after admission when compared to healthy controls (Figure 1). The HMGB1 plasma levels correlated positively with blood inflammatory mediators including activated complement factors (C3a, C5a, Bb, Figure 2A, B and D), MPO (Figure 2F), pro-inflammatory chemokine (MCP-1, Figure 2G)), pro-inflammatory cytokines (IL-6, IL-8, Figure 2H \& I) and anti- 
inflammatory cytokines (IL-10, IL-13 in Figure 2J \& K, respectively) on admission. There was no correlation between HMGB1 and C4d (Figure 2E). The HMGB1 plasma levels on admission also correlated positively with ISS, SIRS, BE/BD (Figure 3B, C, D, respectively), transfusion units of RBCs, PLTs, FFP and infusion units of crystalloids (Figure 3E, F, G, H, respectively). The Glasgow Coma Scale (GCS), a tool used for the assessment of a patient's consciousness, correlated negatively with HMGB1 plasma levels (Figure 3A).

\section{CX-01 partly improved hemodynamics but not blood chemistries}

The MAP in the injured animals was $98.5 \pm 3.0 \mathrm{mmHg}$ at baseline (Figure 4B) and decreased to $38.5 \pm 3.7 \mathrm{mmHg}$ at the end of hemorrhagic shock $(60 \mathrm{~min})$. The MAP was significantly higher two hours post-blast $(62.6 \pm 5.0 \mathrm{mmHg})$ in the injured animals treated with CX-01, but showed no statistical difference when compared with the non-treated injured group $(41.4 \pm 3.7 \mathrm{mmHg})$. There was no statistically significant difference in the MAP between the two experimental groups in further observation. There was no clear difference in BE/BD (Figure 4C), blood lactate (Figure 4D), and potassium levels (Figure 4E) between two groups.

\section{CX-01 reduced systemic inflammatory responses}

The hemolytic activity (CH50) in the blood of the untreated injured rats (group $\mathrm{B}+\mathrm{H}$ ) started to decrease at the end of hemorrhagic shock (60 min), reaching the lowest level at 2 hours, was maintained for the following two hours, but by the end of observation period the CH50 exceeded the baseline level (Figure 5A). In the CX-01-treated injured rats, the CH50 at 2- and 4hours post-blast was significantly higher than the $\mathrm{CH} 50$ value in the non-treated group. This 
showed that the CX-01 reduced complement consumption. The consumption of $\mathrm{C} 1 \mathrm{q}$ was also reduced in the CX-01-treated injured rats at 4 hours when compared to the animals not treated with the drug (Figure 5B), but there was no clear difference in the consumption of $\mathrm{C} 3$ between the two experimental groups (Figure 5C). The HMGB1 blood levels in the rats not treated with CX-01 $(\mathrm{B}+\mathrm{H}$ group) tended to increase at 4 hours post-blast injury but did not reach a statistically significant difference (Figure 6A). The HMGB1 blood concentrations appeared to remain at the basal level in the drug-treated injured animals. There was no clear difference in the MPO (Figure 6B) and MCP-1 (Figure 6C) blood levels between the drug-treated injured rats and those nontreated.

\section{Effects of CX-01 on multiple-organ damage and survival}

Treatment with CX-01 tended to improve survival (Figure 7). Histological assessment revealed that CX-01 treatment reduced MOF severity following $\mathrm{TH}$. After TH, extensive cellular inflammatory infiltrates were present in the pulmonary tissue; the majority of these were neutrophils and macrophages. Lung edema was severe after TH but CX-01 treatment alleviated this phenomenon (Fig. 8A). Typical neuronal apoptosis, neuronal loss, and neuronal degeneration were seen in cerebral cortex and hippocampus, which were significantly reduced by CX-01 treatment (Fig. 8A). TH induced hepatic tissue damage characterized by hepatic cell apoptosis and necrosis. CX-01 treatment alleviated hepatic tissue damage (Fig. 8A). Semi-quantitative scoring of injury severity on histology further validated these observations (Fig. 8B). 


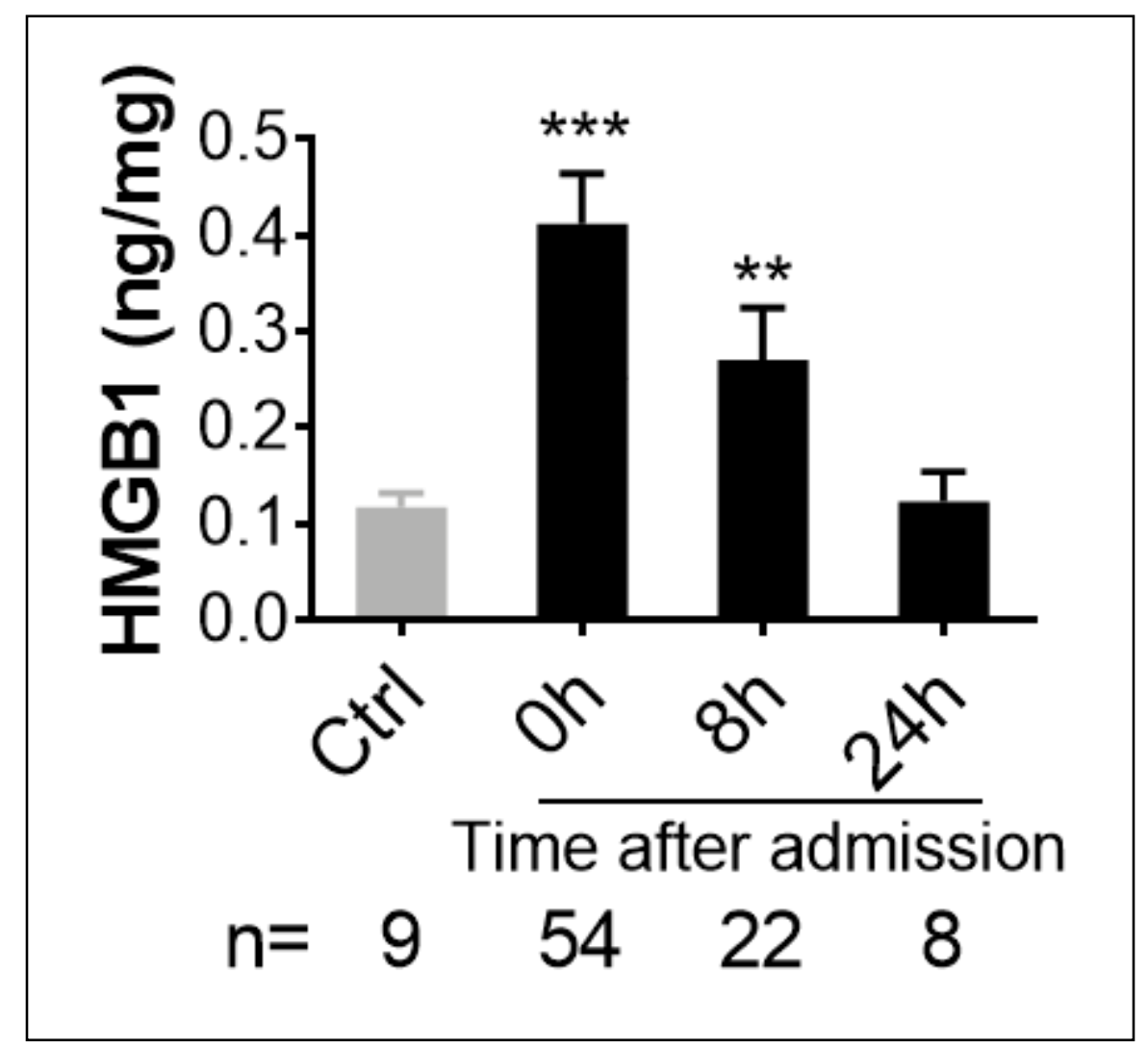

Figure 1. HMGB1 is significantly elevated after injury in trauma patients. Blood plasma from 54 casualties on admission, 8 and 24 hours after admission to a hospital and 9 civilian volunteers (Control, "Healthy") was used for analysis. High mobility group box protein 1 (HMGB1), an inflammatory factor, was measured by ELISA. The data are expressed as nanograms per milligram total plasma proteins and presented as mean $\pm \mathrm{SEM}, * *=p<0.01, * * *=p<0.001 v$ s. Control (Ctrl). 


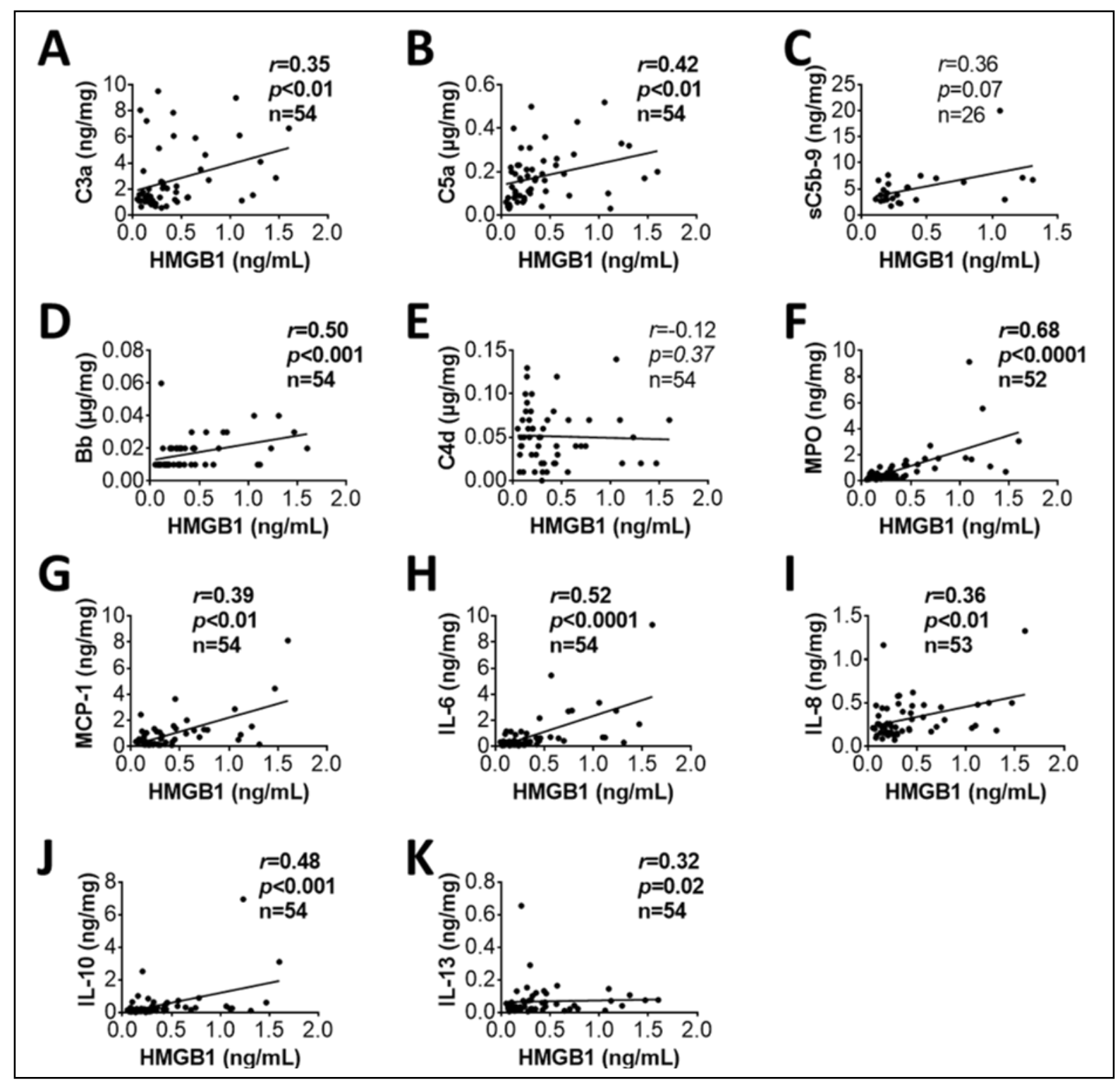

Figure 2. HMGB1 correlated with inflammatory mediators in trauma patients on admission.

Correlations between plasma concentrations of HMGB1 in the casualties and C3a (A), C5a (B), sC5b-9 (C), Bb (D), C4d (E), MPO (F), MCP-1 (G), IL-6 (H), IL-8 (I), IL-10 (J), and IL-13 (K) in the blood plasma of the patients on admission. Correlation analyses were performed by using 
Spearman's rank correlation, and the data are presented with coefficient $\left(\mathrm{r}_{\mathrm{s}}\right)$ and $p$-values.

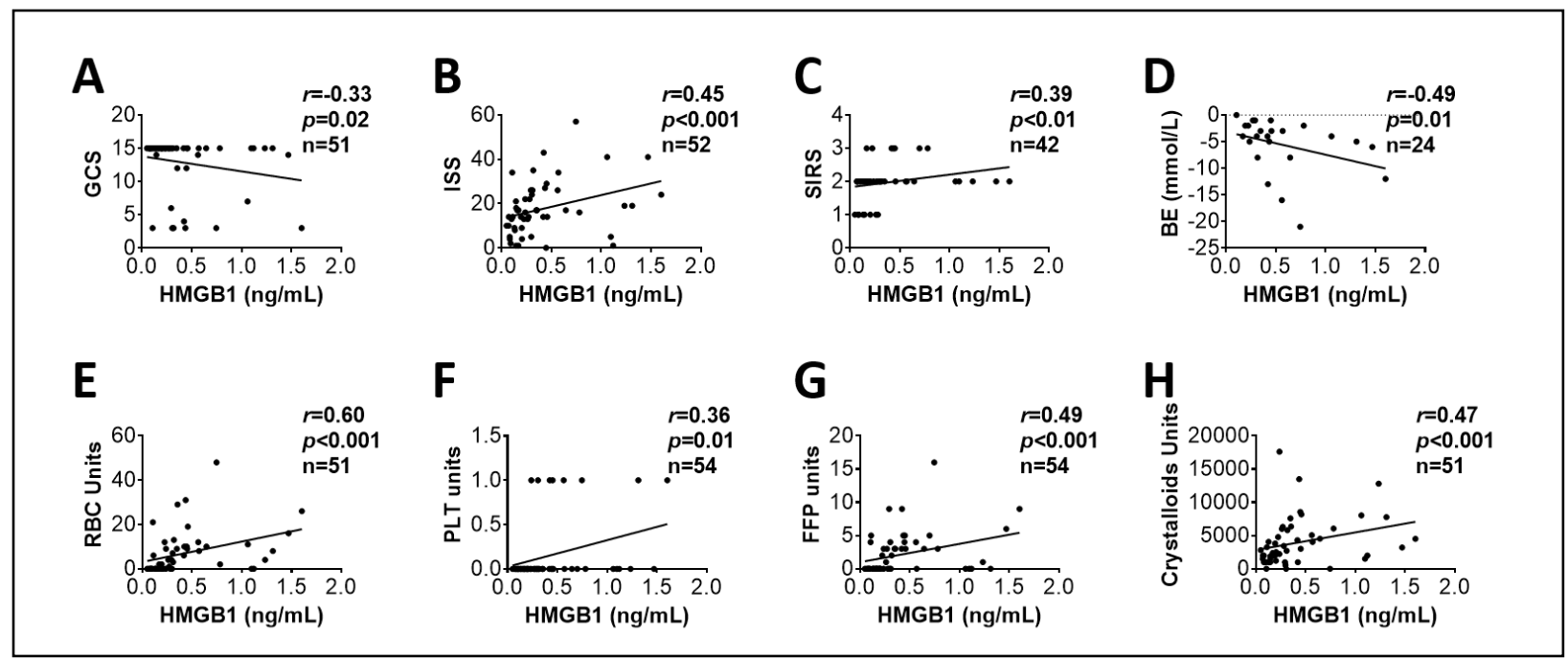

Significant correlations $(\mathrm{p}<0.05)$ are indicated by boldface type.

Figure 3. HMGB1 blood plasma concentrations correlated with clinical outcomes in trauma patients on admission. Positive correlations of HMGB1 blood plasma levels with ISS (B), SIRS (C), units of RBCs (E), units of platelets (F), units of fresh frozen plasma (G), and infused fluid (H). Negative correlations of HMGB1 plasma levels with GCS (A), and BE/BD (D) were observed. Correlation analyses were performed by using Spearman's rank correlation, and the data are presented with coefficient $\left(\mathrm{r}_{\mathrm{s}}\right)$ and $p$-values. Significant correlations $(\mathrm{p}<0.05)$ are indicated by boldface type. 


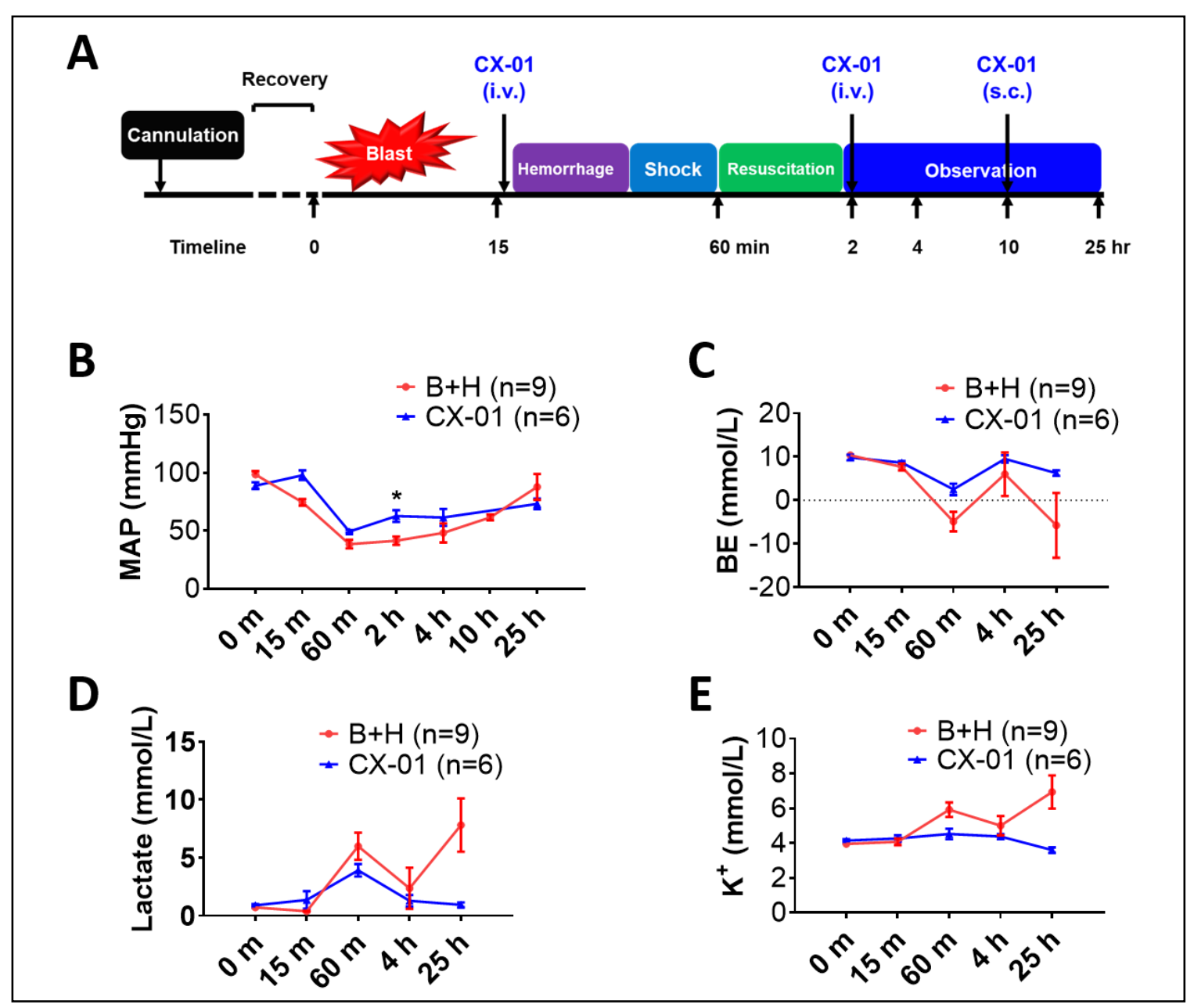

Figure 4. Effects of CX-01 treatment on MAP, and blood chemistry changes in the rat model

of TH. A, experimental design. Experimental groups: (1) $\mathrm{B}+\mathrm{H}=$ blast overpressure + hemorrhagic shock; (2) CX-01-treated injured rats, as marked in Figure A; B, changes of MAP were monitored via the carotid artery by the BIOPAC system and the changes were recorded throughout the study. During shock and resuscitation period, the MAP was recorded every 5 minutes; $\mathbf{C}, \mathrm{BE} / \mathrm{BD} ; \mathbf{D}$, lactate; and E, potassium plasma concentrations are given. Data are presented as mean \pm SEM. The individual time points were compared using the unpaired $t$-test with Welch's correction, and 

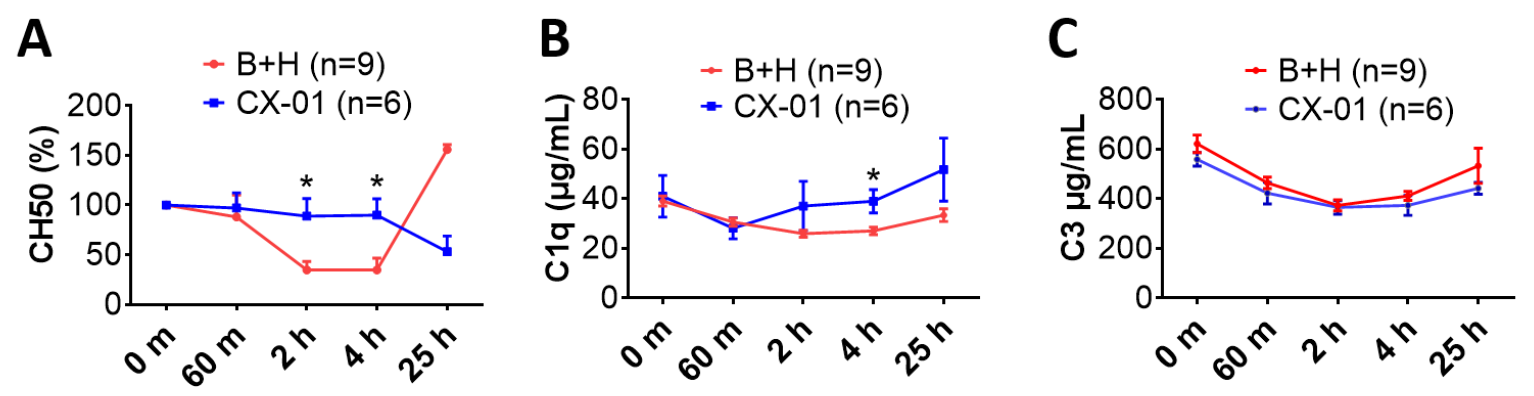

comparison of the groups was performed by two-way ANOVA. $*=p<0.05$ Labels: MAP $=$ mean arterial pressure; $\mathrm{BE} / \mathrm{BD}=$ base excess/base deficit; $\mathrm{K}^{+}=$ionized potassium.

Figure 5. Effects of CX-01 treatment on complement hemolytic activity and complement consumption in the rat model of TH. A, the hemolytic activity (CH50) of sera was measured, and the $\mathrm{CH} 50$ at each time point was normalized to the baseline level, which was pre-blast injury and the percentages of normalization are shown; B, C1q blood serum concentrations; and $\mathbf{C}, \mathrm{C} 3$ blood serum concentrations. Data are presented as mean \pm SEM. The individual time points were compared using the unpaired $t$-test with Welch's correction, and comparison of the groups was performed by two-way ANOVA. ${ }^{*}=\mathrm{p}<0.05$ Labels: $\mathrm{B}+\mathrm{H}=$ blast + hemorrhagic shock; $\mathrm{CX}-01-$ treated injured rats (more details in Figure 4A). 

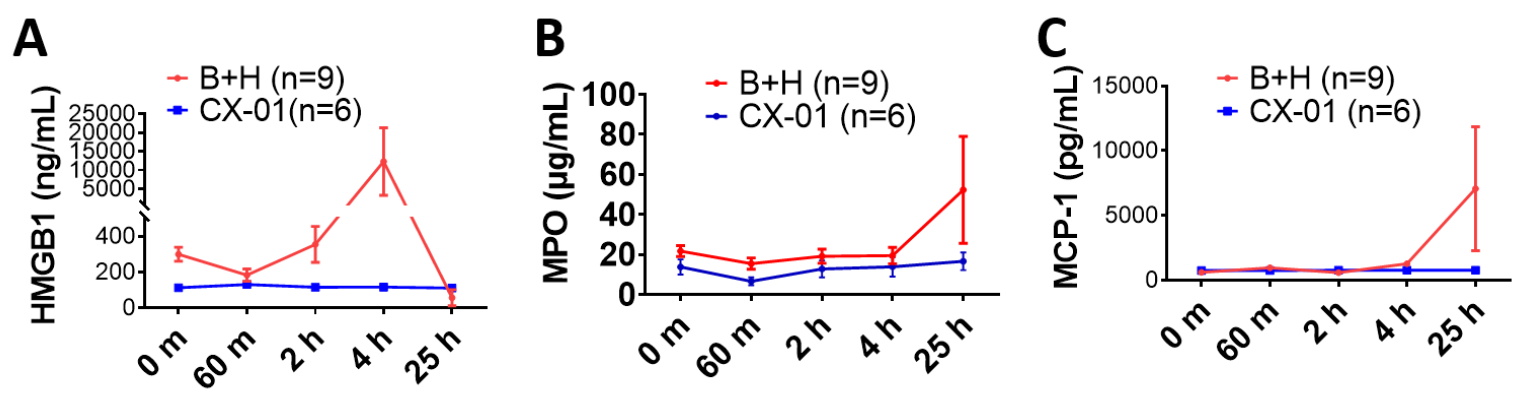

Figure 6. Effects of CX-01 treatment on cytokine concentrations in the rat model of TH. A,

HMGB1 plasma concentrations; B, MPO plasma concentrations; and $\mathbf{C}$, MCP-1 plasma concentrations. Data are presented as mean \pm SEM. Data were compared by using unpaired $t$-test with Welch's correction, and comparison of the groups was performed two-way ANOVA. Labels: $\mathrm{B}+\mathrm{H}=$ blast + hemorrhagic shock; CX-01 -treated injured rats (more details in Figure 4A). 


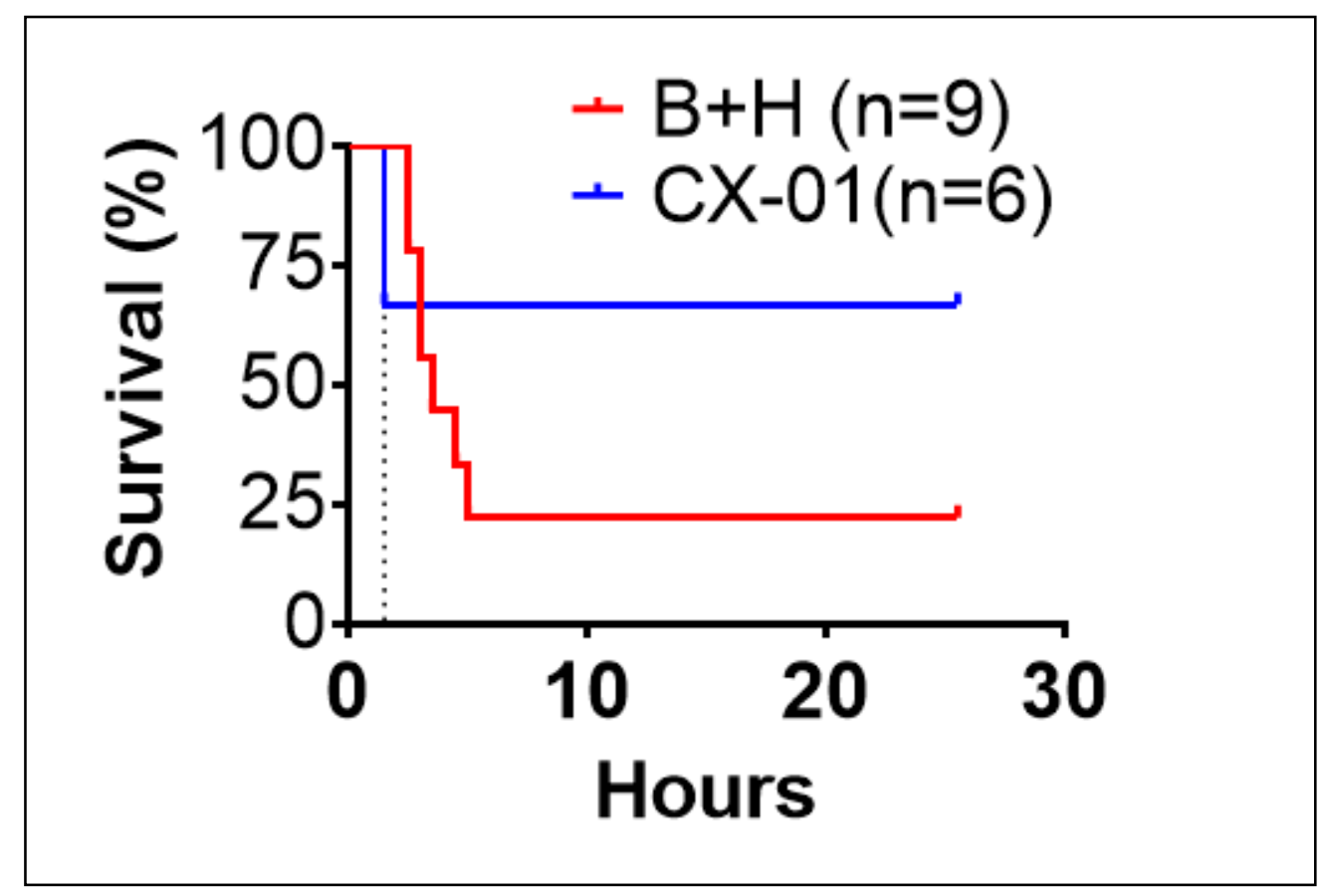

Figure 7. Effect of CX-01 treatment on injury survival in the rat model. Animal survival was monitored up to 24 hours after TH. Survival distribution of these two groups was assessed by the log-rank Mantel-Cox test $(p=0.24)$. 


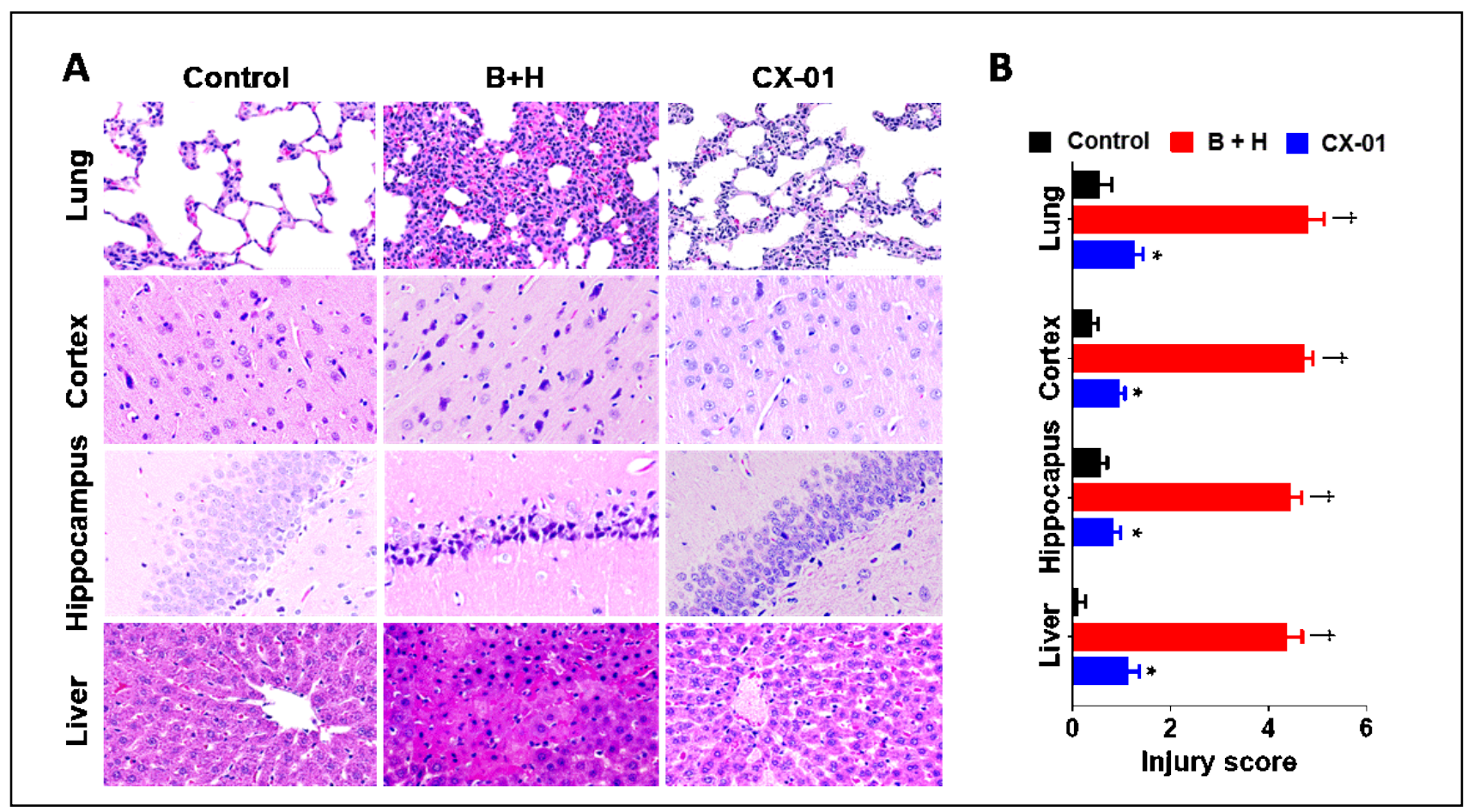

Figure 8. Effect of CX-01 treatment on histological changes in rats after TH. A and B:

Representative $\mathrm{H} \&$ E photomicrographs of organs harvested at the time of necropsy (A) and organ injury was scored based on the criteria described in the Materials and Methods (B). The data are presented as mean $\pm \mathrm{SEM} ; *=p<0.05 \mathrm{CX}-01 v s . \mathrm{B}+\mathrm{H} ; \uparrow=p<0.05$, Control $v s . \mathrm{B}+\mathrm{H}$ (using the Mann-Whitney U test). 


\begin{tabular}{|c|c|c|c|c|c|c|c|c|c|}
\hline & \multicolumn{3}{|c|}{ Reference } & \multicolumn{3}{|c|}{ Overpressure } & \multicolumn{3}{|c|}{ Reflected } \\
\hline & $\overline{\mathrm{P0}(\mathrm{kPa})}$ & $t+(\mathrm{ms})$ & $\bar{I}$ (kPa-ms) & $\overline{\mathrm{P0} \text { (kPa) }}$ & $t+(m s)$ & I (kPa-ms) & P0 (kPa) & $t+(\mathbf{m s})$ & $\bar{I} \mathbf{I}(\mathrm{kPa} a-\mathrm{ms})$ \\
\hline $\mathrm{B}+\mathrm{H}(\mathrm{n}=9)$ & $109.38 \pm 1.27$ & $3.31 \pm 0.01$ & $140.26 \pm 0.86$ & $117.26 \pm 1.36$ & $3.29 \pm 0.01$ & $141.38 \pm 0.87$ & $161.40 \pm 2.07$ & $3.48 \pm 0.03$ & $178.46 \pm 1.35$ \\
\hline CX-01 $(n=6)$ & $109.58 \pm 1.70$ & $3.40 \pm 0.03$ & $143.92 \pm 0.38$ & $117.48 \pm 1.82$ & $3.38 \pm 0.03$ & $145.07 \pm 0.39$ & $162.00 \pm 2.07$ & $3.58 \pm 0.01$ & $182.15 \pm 0.87$ \\
\hline
\end{tabular}

Table 1. Blast wave parameters. Legend: $\mathbf{B}+\mathbf{H}$ group $=$ blast + hemorrhage CX-01 group $=$ blast + CX-01; P0 (peak pressure) in kPa (the kilopascal, a unit of pressure); $\mathbf{t}+$ [the positivepressure phase duration in milliseconds (ms)]; I [impulse (kPa-ms)]. 


\section{DISCUSSION}

In this study, we used a translational medicine approach to identify HMGB1, a damageassociated molecular pattern (DAMP), as a potential therapeutic target in a cohort of military casualties. We selected a heparin derivative (CX-01) that blocks HMGB1 activity and that has properties suitable for prehospital use in trauma patients. Finally, we assessed the efficacy of CX01 on morbidity and mortality in rats subjected to blast injury and hemorrhagic shock.

We first investigated the relationship between HMGB1 blood concentrations, inflammatory mediators, and clinical outcomes in military casualties. We found significantly increased plasma concentrations of HMGB1 in the casualties on arrival to the hospital. Since field care and transportation of the casualties to the hospital took only 15-45 minutes in our study, this suggests that injury causes prompt release of HMGB1. In some reports, eHMGB1 has been considered a relatively delayed mediator of inflammation when compared with TNF and IL-1 [24]. On the other hand, HMGB1 concentration was increased in the serum 1 hour after bilateral femur fracture in mice [36]. Similarly, in patients with mechanical trauma (ISS $\geq 15$ ), plasma HMGB1 was increased more than 30-fold when compared to healthy controls within 1 hour of injury; marked elevations were observed from 2 to 6 hours after trauma. In contrast to late involvement of HMGB1 in endotoxin lethality in mice [38], it was released early after blunt or penetrating trauma [37]. In severe trauma patients without previous coagulation abnormalities, Cohen et al. showed that plasma levels of HMGB1 increased within 30 minutes after severe blunt or penetrating injury [39]. In a recent study in severe trauma patients, Ottestad et al. showed a biphasic release of HMGB1; a second peak 3-6 hours after trauma was the most reliable predictor of outcome [40].

What is the cause and what is the effect of early eHMGB1 release following injury? HMGB1, a nuclear protein, has multiple functions that depend on its location in nucleus, cytosol, 
or extracellular space. Movement of HMGB1 between these compartments is dynamic process, and it can be actively or passively released into the extracellular space during trauma, hemorrhagic shock, stress and/or sepsis [41-43]. eHMGB1 release after sepsis and trauma-induced inflammatory responses (cytokine storm, neutrophil extracellular trap formation, etc.,), delivery of LPS into the cytoplasm, pyroptosis, oxidative stress, platelet activation and thrombosis, and endothelial/mucosal barrier dysfunction [41]. The recognition of eHMGB1 by pattern-recognition receptors (PRR) such as the cell-surface receptor for advanced glycation end products (RAGE), and toll-like receptors (TLR2 and TLR4) promotes inflammation. eHMGB1 causes inflammation by itself or in complex with other pro-inflammatory molecules (e.g., DNA, RNA, histones, nucleosomes, lipopolysaccharide, SDF-1 IL-1 $\alpha$, IL-1 $\beta$ ) [44]. When HMGB1 acts alone as a proinflammatory cytokine, the redox status of HMGB1 has a crucial role [44]. Mild HMGB1 oxidation generating a disulfide bond between Cys23 and Cys45 while maintaining Cys106 in the reduced form transforms eHMGB1 into a powerful catalyst of the generation of pro-inflammatory cytokines via TLR4 receptor stimulation [45].

HMGB1 can be a harmful self-derived molecule, the major DAMP that is recognized by PRRs secreted by immune cells or expressed on them [46-48]. Thus, HMGB1 triggers a sterile inflammatory reaction which leads to priming and activation of so-called NOD-, LRR- and pyrin domain-containing protein 3 (NLRP3) inflammasomes, and in turn NLRP3-inflammasome activation results in active HMGB1 release (48). This inflammation pathway is activated via the axis of HMGB1-TLR2/4/RAGE-NF-אB-NLRP3/caspase-1, and/or HMGB1-CXCL12-CXCR4NF-кB-NLRP3/caspase-1 [22, 48-51].

Crosstalk between eHMGB1 and complement cascade has been suggested. Growing evidence in IRI indicates that their interaction is found through the axis of eHMGB1-properdin (a 
positive regulator of complement alternative pathway) [52], C5a-C5aR2-NF-кB-NLRP3/caspase1-HMGB1 [53], or C5a-C5aR2-MAPK-HMGB1-TLRs/RAGE-MAPK-NLRP3/caspase-1 [54]. The interaction between HMGB1 and complement cascade may play an important role in THinduced inflammatory response and inflammation-mediated MOF after TH. The relationship between eHMGB1 and the complement system has also been examined in IRI studies. These studies have reported that HMGB1-C1q interaction initiates complement activation and regulates inflammatory responses $[55,56]$; the complement receptor C5aR2 has been shown to contribute to NLRP3 inflammasome activation and HMGB1 release from murine macrophages in vitro and in vivo $[53,54]$.

Consistent with the crosstalk concept, in military casualties, we showed that elevated HMGB1 levels were associated with complement alternative $(\mathrm{Bb}) /$ terminal pathway activation (C5a), MPO plasma levels, and plasma levels of a pro-inflammatory chemokine (MCP-1) and proinflammatory cytokines (IL-6, IL-8), as well as anti-inflammatory cytokines (IL-10, IL-13). Early plasma elevations of HMGB1 were also associated with some clinical outcomes, including GCS, ISS, SIRS, blood base deficit, coagulopathy, and fresh frozen plasma and fluid resuscitation requirements.

In injured rats, we observed that the $\mathrm{CH} 50$ value was reduced about $70 \%$ one hour after hemorrhagic shock. This decrease of $\mathrm{CH} 50$ indicates rapid systemic complement activation after injury. Using the same trauma model, we have previously showed complement deposition in the lung tissue, including C5b-9 and C3 (unpublished data). These findings indicate that both systemic and local complement activation occurred in injured animals. A clearly increased CH50 (up to $150 \%$ ) at the end of the observation period coincided with inflammation in target tissues, and a significant increase in organ-injury scores. Gruys et al. explained highly increased $\mathrm{CH} 50$ as an 
indicator of the systemic acute-phase immune response that involves increased pro-inflammatory cytokines and C3 [57].

In our study, we found that CX-01, an inhibitor of HMGB1 that blocks systemic HMGB1 release, reduced early complement consumption and therefore, complement activation; CX-01 also reduced consumption of $\mathrm{C} 1 \mathrm{q}$ but there were no effects on $\mathrm{C} 3$ levels. A molecular mechanism of CX-01 in the inhibition of complement activation and C1q consumption in this study might be due to the potentiation of $\mathrm{C} 1$ inhibitor activity by $\mathrm{CX}-01$ [58]. Previous studies have demonstrated that early administration of CX-01 increased survival and ameliorated lung injury in mice after Pseudomonas infection [35]. It also reduced brain damage and neuroinflammation, and improved acute neurologic recovery in mice after TBI [59]. CX-01, one of the minimal anticoagulant desulfated heparins, does not cause heparin-induced thrombocytopenia but retains multiple antiinflammatory properties, including inhibition of RAGE-HMGB1 interaction [60]. Exploratory in vitro studies in the context of tumor immunotherapy have shown that CX-01 may also interfere with the CXCL12/CXCR4 axis [61]. There are other approaches to HMGB1 activity inhibition, including anti-HMGB1 antibodies. These studies have reported that inhibition of the HMGB1mediated inflammatory signals improved outcomes in TBI and hemorrhagic shock [62, 63].

Taken together, our clinical and preclinical findings show that HMGB1 plays a critical role in the pathogenesis of trauma and hemorrhage, and that CX-01 may be a promising pharmacological solution for the treatment of severely injured patients in pre-hospital settings. While treatment with CX-01 clearly reduced tissue damage in some target organs of the injured rats, verifying the effect of CX-01 on survival would require a larger number of rats. Likewise, confirmation of such an effect would require studies in large animals. 
Funding: This research was supported by the DoD US Army Medical Research \& Development Command (C_038_2014) and by the DoD US Army Medical Research \& Development Command FY15 Broad Agency Announcement (BA150301).

Author Contributions: ZY, MOS, BL, PRE, and YL performed the experiments, collected data, measured samples and summarized data. ZY and MOS conducted data statistical analysis. MOS wrote the manuscript. ZY, TSC, PRE, AIB, LCC, and YL reviewed and critically revised the manuscript. LCC and YL designed the overall study and interpreted data.

\section{Institutional Review Board Statement}

Foreign nationals, prisoners, enemy combatants, and any patient undergoing therapeutic anticoagulation, were excluded. The institutional review board of Brooke Army Medical Center reviewed and approved the research protocol and granted a waiver of consent for blood sampling as a minimal-risk intervention.

Data Availability Statement: All data generated or analyzed during the current study are included in this published manuscript.

Conflict of Interest: The authors declare that they have no conflicts of interest relevant to the manuscript submitted to Journal of Biomolecules. The opinions or assertions contained herein are the private views of the authors and are not to be construed as official or as reflecting the views of the Department of the Army or the Department of Defense. 
Informed Consent Statement: not applicable.

\section{REFERENCES}

1. Chambers JA, Seastedt K, Krell R, Caterson E, Levy M, Turner N. Stop the Bleed": A U.S. Military Installation's Model for Implementation of a Rapid Hemorrhage Control Program. Mil Med. 2019, 184, 67-71. doi: 10.1093/milmed/usy185.

2. Lord JM, Midwinter MJ, Chen YF, Belli A, Brohi K, Kovacs EJ, Koenderman L, Kubes P, Lilford RJ. The systemic immune response to trauma: an overview of pathophysiology and treatment. Lancet. 2014, 384:1455-1465. doi: 10.1016/S0140-6736(14)60687-5.

3. Cannon JW. Hemorrhagic Shock. N Engl J Med. 2018, 378, 370-379. doi: 10.1056/NEJMra1705649.

4. Roquilly A, Lejus C, Asehnoune K. Agressions cérébrales, immunité et infections [Brain injury, immunity and infections]. Ann Fr Anesth Reanim. 2012, 31, e97-100. French. doi: 10.1016/j.annfar.2012.04.012.

5. Osuka A, Ogura H, Ueyama M, Shimazu T, Lederer JA. Immune response to traumatic injury: harmony and discordance of immune system homeostasis. Acute Med Surg. 2014 1, 63-69. doi: 10.1002/ams2.17.

6. Huber-Lang M, Lambris JD, Ward PA. Innate immune responses to trauma. Nat Immunol. 2018, 19, 327-341. doi: 10.1038/s41590-018-0064-8.

7. Levy RM, Mollen KP, Prince JM, Kaczorowski DJ, Vallabhaneni R, Liu S, Tracey KJ, Lotze MT, Hackam DJ, Fink MP, Vodovotz Y, Billiar TR. Systemic inflammation and remote organ injury following trauma require HMGB1. Am J Physiol Regul Integr Comp Physiol. 2007, 293, R1538-R1544. doi: 10.1152/ajpregu.00272.2007. 
8. Laird MD, Shields JS, Sukumari-Ramesh S, Kimbler DE, Fessler RD, Shakir B, Youssef P, Yanasak N, Vender JR, Dhandapani KM. High mobility group box protein-1 promotes cerebral edema after traumatic brain injury via activation of toll-like receptor 4. Glia. 2014, 62, 26-38. doi: 10.1002/glia.22581.

9. Relja B, Mörs K, Marzi I. Danger signals in trauma. Eur J Trauma Emerg Surg. 2018, 44, 301-316. doi: 10.1007/s00068-018-0962-3.

10. Cheng Z, Abrams ST, Alhamdi Y, Toh J, Yu W, Wang G, Toh CH. Circulating histones are major mediators of multiple organ dysfunction syndrome in acute critical illnesses. Crit Care Med. 2019, 47, e677-e684. doi: 10.1097/CCM.0000000000003839.

11. Zhao H, Kilgas S, Alam A, Eguchi S, Ma D. The Role of Extracellular Adenosine Triphosphate in Ischemic Organ Injury. Crit Care Med. 2016, 44:1000-1012. doi: 10.1097/CCM.0000000000001603.

12. Davis GE, Bayless KJ, Davis MJ, Meininger GA. Regulation of tissue injury responses by the exposure of matricryptic sites within extracellular matrix molecules. Am J Pathol. 2000, 156, 1489-1498. doi: 10.1016/S0002-9440(10)65020-1.

13. Rittirsch D, Schoenborn V, Lindig S, Wanner E, Sprengel K, Günkel S, Blaess M, Schaarschmidt B, Sailer P, Märsmann S, Simmen HP, Cinelli P, Bauer M, Claus RA, Wanner GA. An Integrated Clinico-transcriptomic Approach Identifies a Central Role of the Heme Degradation Pathway for Septic Complications after Trauma. Ann Surg. 2016, 264, 1125-1134. doi: 10.1097/SLA.0000000000001553.

14. Qiang X, Yang WL, Wu R, Zhou M, Jacob A, Dong W, Kuncewitch M, Ji Y, Yang H, Wang H, Fujita J, Nicastro J, Coppa GF, Tracey KJ, Wang P. Cold-inducible RNA-binding 
protein (CIRP) triggers inflammatory responses in hemorrhagic shock and sepsis. Nat Med. 2013, 19, 1489-1495. doi: 10.1038/nm.3368.

15. Zhang Q, Raoof M, Chen Y, Sumi Y, Sursal T, Junger W, Brohi K, Itagaki K, Hauser CJ. Circulating mitochondrial DAMPs cause inflammatory responses to injury. Nature. 2010, 464, 104-107. doi: 10.1038/nature08780.

16. Burk AM, Martin M, Flierl MA, Rittirsch D, Helm M, Lampl L, Bruckner U, Stahl GL, Blom AM, Perl M, Gebhard F, Huber-Lang M. Early complementopathy after multiple injuries in humans. Shock. 2012, 37, 348-54. doi: 10.1097/SHK.0b013e3182471795.

17. Chang R, Cardenas JC, Wade CE, Holcomb JB. Advances in the understanding of traumainduced coagulopathy. Blood. 2016, 128, 1043-1049. doi: 10.1182/blood-2016-01636423.

18. Rodell TC. The kallikrein/kinin system and kinin antagonists in trauma. Immunopharmacology. 1996, 33, 279-283. doi: 10.1016/0162-3109(96)00071-9.

19. Jiang L, Shao Y, Tian Y, Ouyang C, Wang X. Nuclear Alarmin Cytokines in Inflammation. J Immunol Res. 2020, 2020:7206451. doi: 10.1155/2020/7206451.

20. Andersson U, Tracey KJ. HMGB1 is a therapeutic target for sterile inflammation and infection. Annu Rev Immunol. 2011, 29, 139-62. doi: 10.1146/annurev-immunol-030409101323.

21. Ma KC, Schenck EJ, Pabon MA, Choi AMK. The Role of Danger Signals in thePathogenesis and Perpetuation of Critical Illness. Am J Respir Crit Care Med.2018 Feb 1;197(3):300-309. doi: 10.1164/rccm.201612-2460PP. 
22. Venereau E, Schiraldi M, Uguccioni M, Bianchi ME. HMGB1 and leukocyte migration during trauma and sterile inflammation. Mol Immunol. 2013Aug;55(1):76-82. doi: 10.1016/j.molimm.2012.10.037.

23. Vincent JL, Opal SM, Marshall JC, Tracey KJ. Sepsis definitions: time for change. Lancet. 2013, 381, 774-775. doi: 10.1016/S0140-6736(12)61815-7.

24. Lotze MT, Tracey KJ. High-mobility group box 1 protein (HMGB1): nuclear weapon in the immune arsenal. Nat Rev Immunol. 2005, 5, 331-342. doi: 10.1038/nri1594.

25. Campbell JC, Li Y, van Amersfoort E, Relan A, Dubick M, Sheppard F, Pusateri A, Niemeyer D, Tsokos GC, Dalle Lucca JJ. C1 Inhibitor Limits Organ Injury and Prolongs Survival in Swine Subjected to Battlefield Simulated Injury. Shock. 2016, 46 (3 Suppl 1):177-188. doi: 10.1097/SHK.0000000000000677.

26. Dalle Lucca JJ, Simovic M, Li Y, Moratz C, Falabella M, Tsokos GC. Decay-accelerating factor mitigates controlled hemorrhage-instigated intestinal and lung tissue damage and hyperkalemia in swine. J Trauma. 2011, 71(1 Suppl), S151-S160. doi: 10.1097/TA.0b013e318221aa4c.

27. Dalle Lucca JJ, Li Y, Simovic MO, Slack JL, Cap A, Falabella MJ, Dubick M, Lebeda F, Tsokos GC. Decay-accelerating factor limits hemorrhage-instigated tissue injury and improves resuscitation clinical parameters. J Surg Res. 2013, 179, 153-167. doi: 10.1016/j.jss.2012.10.017.

28. Dalle Lucca JJ, Li Y, Simovic M, Pusateri AE, Falabella M, Dubick MA, Tsokos GC. Effects of $\mathrm{C} 1$ inhibitor on tissue damage in a porcine model of controlled hemorrhage. Shock. 2012, 38, 82-91. doi: 10.1097/SHK.0b013e31825a3522. 
29. Musumeci D, Roviello GN, Montesarchio D. An overview on HMGB1 inhibitors as potential therapeutic agents in HMGB1-related pathologies. Pharmacol Ther. 2014, 141,347-357. doi: 10.1016/j.pharmthera.2013.11.001.

30. Vijayakumar EC, Bhatt LK, Prabhavalkar KS. High Mobility Group Box-1 (HMGB1): A Potential Target in Therapeutics. Curr Drug Targets. 2019, 20, 1474-1485. doi: $10.2174 / 1389450120666190618125100$.

31. Yang Z, Aderemi OA, Zhao Q, Edsall PR, Simovic MO, Lund BJ, Espinoza MD, Woodson AM, Li Y, Cancio LC. Early Complement and Fibrinolytic Activation in a Rat Model of Blast-Induced Multi-Organ Damage. Mil Med. 2019, 184(Suppl 1):282-290. doi: 10.1093/milmed/usy412.

32. Lusczek ER, Muratore SL, Dubick MA, Beilman GJ. Assessment of key plasma metabolites in combat casualties. J Trauma Acute Care Surg. 2017, 82, 309-316. doi: 10.1097/TA.0000000000001277.

33. Chavko M, Adeeb S, Ahlers ST, McCarron RM. Attenuation of pulmonary inflammation after exposure to blast overpressure by N-acetylcysteine amide. Shock. 2009, 32, 325-331. doi: 10.1097/SHK.0b013e31819c38f1.

34. Li Y, Chavko M, Slack JL, Liu B, McCarron RM, Ross JD, Dalle Lucca JJ. Protective effects of decay-accelerating factor on blast-induced neurotrauma in rats. Acta Neuropathol Commun. 2013, 1, 52. doi: 10.1186/2051-5960-1-52.

35. Sharma L, Wu J, Patel V, Sitapara R, Rao NV, Kennedy TP, Mantell LL. Partiallydesulfated heparin improves survival in Pseudomonas pneumonia by enhancing bacterial clearance and ameliorating lung injury. J Immunotoxicol. 2014 Jul-Sep;11(3):260-7. doi: 10.3109/1547691X.2013.839587. 
36. Levy RM, Mollen KP, Prince JM, Kaczorowski DJ, Vallabhaneni R, Liu S, Tracey KJ, Lotze MT, Hackam DJ, Fink MP, Vodovotz Y, Billiar TR. Systemic inflammation and remote organ injury following trauma require HMGB1. Am J Physiol Regul Integr Comp Physiol. 2007, 293, R1538-R1544 doi: 10.1152/ajpregu.00272.2007.

37. Wang H, Bloom O, Zhang M, Vishnubhakat JM, Ombrellino M, Che J, Frazier A, Yang H, Ivanova S, Borovikova L, Manogue KR, Faist E, Abraham E, Andersson J, Andersson U, Molina PE, Abumrad NN, Sama A, Tracey KJ. HMG-1 as a late mediator of endotoxin lethality in mice. Science. 1999, 285, 248-251. doi: 10.1126/science. 285.5425.248.

38. Peltz ED, Moore EE, Eckels PC, Damle SS, Tsuruta Y, Johnson JL, Sauaia A, Silliman CC, Banerjee A, Abraham E. HMGB1 is markedly elevated within 6 hours of mechanical trauma in humans. Shock. 2009, 32, 17-22. doi: 10.1097/shk.0b013e3181997173.

39. Cohen MJ, Brohi K, Calfee CS, Rahn P, Chesebro BB, Christiaans SC, Carles M, Howard M, Pittet JF. Early release of high mobility group box nuclear protein 1 after severe trauma in humans: role of injury severity and tissue hypoperfusion. Crit Care. 2009, 13, R174. doi: $10.1186 / \mathrm{cc} 8152$.

40. Ottestad W, Rognes IN, Pischke SE, Mollnes TE, Andersson U, Eken T. Biphasic Release of the Alarmin High Mobility Group Box 1 Protein Early After Trauma Predicts Poor Clinical Outcome. Crit Care Med. 2019, 47, e614-e622. doi: 10.1097/ CCM. 0000000000003800.

41. Deng M, Scott MJ, Fan J, Billiar TR. Location is the key to function: HMGB1 in sepsis and trauma-induced inflammation. J Leukoc Biol. 2019, 106, 161-169. doi: 10.1002/JLB.3MIR1218-497R.

42. Ge Y, Huang M, Yao YM. The Effect and Regulatory Mechanism of High Mobility 
Group Box-1 Protein on Immune Cells in Inflammatory Diseases. Cells. 2021 Apr 28;10(5):1044. doi: 10.3390/cells10051044.

43. Li Y, Yang Z, Chavko M, Liu B, Aderemi OA, Simovic MO, Dubick MA, Cancio LC. Complement inhibition ameliorates blast-induced acute lung injury in rats: Potential role of complement in intracellular HMGB1-mediated inflammation. PLoS One. 2018 Aug 22;13(8):e0202594. doi: 10.1371/journal.pone.0202594.

44. Yang H, Wang H, Andersson U. Targeting Inflammation Driven by HMGB1. Front Immunol. 2020, 11, 484. doi: 10.3389/fimmu.2020.00484.

45. Yang H, Hreggvidsdottir HS, Palmblad K, Wang H, Ochani M, Li J, Lu B, Chavan S, Rosas-Ballina M, Al-Abed Y, Akira S, Bierhaus A, Erlandsson-Harris H, Andersson U, Tracey KJ. A critical cysteine is required for HMGB1 binding to Toll-like receptor 4 and activation of macrophage cytokine release. Proc Natl Acad Sci U S A. 2010, 107, 1194211947. doi: 10.1073/pnas.1003893107.

46. Arbore G, Kemper C. A novel "complement-metabolism-inflammasome axis" as a key regulator of immune cell effector function. Eur J Immunol. 2016, 46, 1563-1573. doi: 10.1002/eji.201546131.

47. Roh JS, Sohn DH. Damage-Associated Molecular Patterns in Inflammatory Diseases. Immune Netw. 2018, 18, e27. doi: 10.4110/in.2018.18.e27.

48. Gong T, Liu L, Jiang W, Zhou R. DAMP-sensing receptors in sterile inflammation and inflammatory diseases. Nat Rev Immunol. 2020 Feb;20(2):95-112. doi: 10.1038/s41577019-0215-7

49. Dowling JK, O'Neill LA. Biochemical regulation of the inflammasome. Crit Rev Biochem Mol Biol. 2012, 47, 424-443. doi: 10.3109/10409238.2012.694844. 
50. Andersson U, Yang H, Harris H. Extracellular HMGB1 as a therapeutic target in inflammatory diseases. Expert Opin Ther Targets. 2018, 22, 263-277. doi: 10.1080/14728222.2018.1439924.

51. Swanson KV, Deng M, Ting JP. The NLRP3 inflammasome: molecular activation and regulation to therapeutics. Nat Rev Immunol. 2019, 19, 477-489. doi: 10.1038/s41577-0190165-0.

52. Zwaini Z, Dai H, Stover C, Yang B. Role of Complement Properdin in Renal Ischemia-Reperfusion Injury. Curr Gene Ther. 2017;17(6):411-423. doi: $10.2174 / 1566523218666180214093043$.

53. Yu S, Wang D, Huang L, Zhang Y, Luo R, Adah D, Tang Y, Zhao K, Lu B. The complement receptor $\mathrm{C} 5 \mathrm{aR} 2$ promotes protein kinase $\mathrm{R}$ expression and contributes to NLRP3 inflammasome activation and HMGB1 release from macrophages. J Biol Chem. 2019, 294, 8384-8394. doi:10.1074/jbc.RA118.006508.

54. Eppensteiner J, Kwun J, Scheuermann U, Barbas A, Limkakeng AT, Kuchibhatla M, Elster EA, Kirk AD, Lee J. Damage- and pathogen-associated molecular patterns play differential roles in late mortality after critical illness. JCI Insight. 2019, 4, e127925. doi: 10.1172/ jci.insight. 127925 .

55. Kim SY, Son M, Lee SE, Park IH, Kwak MS, Han M, Lee HS, Kim ES, Kim JY, Lee JE, Choi JE, Diamond B, Shin JS. High-Mobility Group Box 1-Induced Complement Activation Causes Sterile Inflammation. Front Immunol. 2018 Apr 11;9:705. doi: 10.3389/fimmu.2018.00705.

56. Liu T, Xiang A, Peng T, Doran AC, Tracey KJ, Barnes BJ, Tabas I, Son M, Diamond B. HMGB1-C1q complexes regulate macrophage function by switching between 
leukotriene and specialized proresolving mediator biosynthesis. Proc Natl Acad Sci U S A. 2019 Nov 12;116(46):23254-23263. doi: 10.1073/pnas. 1907490116.

57. Gruys E, Toussaint MJ, Niewold TA, Koopmans SJ. Acute phase reaction and acute phase proteins. J Zhejiang Univ Sci B. 2005, 6, 1045-1056. doi: 10.1631/jzus.2005.B1045.

58. Calswell EE, Andreasen AM, Blietz MA, Serrahn JN, VanderNoot V, et al. Heparin binding and augmentation of C1 inhibitor activity. Archiv Biochem Biophys. 1999; 261:215-222

59. Nagata K, Suto Y, Cognetti J, Browne KD, Kumasaka K, Johnson VE, Kaplan L, Marks J, Smith DH, Pascual JL. Early low-anticoagulant desulfated heparin after traumatic brain injury: Reduced brain edema and leukocyte mobilization is associated with improved watermaze learning ability weeks after injury. J TraumaAcute Care Surg. 2018 May;84(5):727-735. doi: 10.1097/TA.0000000000001819.

60. Kovacsovics TJ, Mims A, Salama ME, Pantin J, Rao N, Kosak KM, Ahorukomeye P, Glenn MJ, Deininger MWN, Boucher KM, Bavisotto LM, Gutierrez-Sanchez G, Kennedy TP, Marcus SG, Shami PJ. Combination of the low anticoagulant heparin CX-01 with chemotherapy for the treatment of acute myeloid leukemia. Blood Adv. 2018, 2, 381-389. doi: 10.1182/bloodadvances.201701339

61. Rao NV, Argyle B, Xu X, Reynolds PR, Walenga JM, Prechel M, Prestwich GD, MacArthur RB, Walters BB, Hoidal JR, Kennedy TP. Low anticoagulant heparin targets multiple sites of inflammation, suppresses heparin-induced thrombocytopenia, and inhibits interaction of RAGE with its ligands. Am J Physiol Cell Physiol. 2010, 299, C97- C110. doi: 10.1152/ajpcell.00009.2010. 
62. Okuma Y, Liu K, Wake H, Zhang J, Maruo T, Date I, Yoshino T, Ohtsuka A, Otani N, Tomura S, Shima K, Yamamoto Y, Yamamoto H, Takahashi HK, Mori S, Nishibori M. Anti-high mobility group box-1 antibody therapy for traumatic brain injury. Ann Neurol. 2012, 72, 373-384. doi: 10.1002/ana.23602.

63. Yang R, Harada T, Mollen KP, Prince JM, Levy RM, Englert JA, Gallowitsch-Puerta M, Yang L, Yang H, Tracey KJ, Harbrecht BG, Billiar TR, Fink MP. Anti-HMGB1 neutralizing antibody ameliorates gut barrier dysfunction and improves survival after hemorrhagic shock. Mol Med. 2006, 12, 105-114. doi: 10.2119/2006-00010. 